\title{
Antiretroviral treatment reverses HIV-associated anemia in rural Tanzania
}

Asgeir Johannessen ${ }^{1 *}$, Ezra Naman², Svein G Gundersen ${ }^{3,4}$ and Johan N Bruun 1,5,6

\begin{abstract}
Background: HIV-associated anemia is common and associated with poor prognosis. However, its response to antiretroviral treatment (ART) in rural Africa is poorly understood.

Methods: HIV-infected adults ( $\geq 15$ years) who enrolled in HIV care at Haydom Lutheran Hospital in northern Tanzania were included in the study. The effect of ART (zidovudine/stavudine + lamivudine + efavirenz/nevirapine) on HIV-associated anemia was studied in a subset of patients who were anemic at the time they started ART and had a follow-up hemoglobin measurement 12 months later. Pregnant women were excluded from the study, as were women who had given birth within the past 6 weeks. Anemia was defined as hemoglobin $<12 \mathrm{~g} / \mathrm{dL}$ in women and $<13 \mathrm{~g} / \mathrm{dL}$ in men. We applied paired sample T-tests to compare hemoglobin levels before and one year after ART initiation, and logistic regression models to identify predictors of persistent anemia.

Results: At enrollment, mean hemoglobin was $10.3 \mathrm{~g} / \mathrm{dL}$, and 649 of 838 patients (77.4\%) were anemic. Of the anemic patients, 254 (39.1\%) had microcytosis and hypochromia. Among 102 patients who were anemic at ART initiation and had a follow-up hemoglobin measurement after 12 months, the mean hemoglobin increased by 2.5 $\mathrm{g} / \mathrm{dL}(P<0.001)$; however, 39 patients (38.2\%) were still anemic after 12 months of ART. Independent predictors of persistent anemia were mean cell volume in the lower quartile ( $<76.0 \mathrm{fL}$; Odds Ratio [OR] 4.34; $95 \%$ confidence interval $[\mathrm{Cl}] 1.22-15.5)$ and a zidovudine-containing initial regimen (OR 2.91; 95\% Cl 1.03-8.19).

Conclusions: Most patients had anemia at enrollment, of whom nearly $40 \%$ had microcytosis and hypochromia suggestive of iron deficiency. The mean hemoglobin increased significantly in patients who received ART, but one third were still anemic 12 months after ART initiation indicating that additional interventions to treat HIV-associated anemia in rural Africa might be warranted, particularly in patients with microcytosis and those treated with zidovudine.
\end{abstract}

\section{Background}

Anemia is a common feature of HIV infection, occurring in approximately $35 \%$ of patients who initiate antiretroviral treatment (ART) in Europe and North America [1]. In addition to causing reduced physical functioning and quality of life, a number of studies have found that anemia at the time of ART initiation is associated with HIV disease progression and mortality [2-9]. Indeed, in the EuroSIDA cohort, patients with severe anemia at baseline had 13 times greater risk of death during the first year of ART than patients with normal hemoglobin levels [3]. Similar findings have recently

\footnotetext{
* Correspondence: asgeir.johannessen@medisin.uio.no

'Department of Infectious Diseases, Oslo University Hospital, Ulleval, Oslo, Norway

Full list of author information is available at the end of the article
}

been reported from Tanzania, Côte d'Ivoire, South Africa and Malawi $[2,6,8]$.

It is uncertain whether the association between anemia and mortality is causal or whether anemia acts as a surrogate marker of underlying disease. Previous studies have found that the incidence of anemia increases with progression of HIV infection [9-11], and anemia is a known feature of certain opportunistic infections such as tuberculosis (TB), atypical mycobacteria and parvovirus B19 [12]. Several other etiologic factors may also be involved in the development of HIV-associated anemia, including micronutrient deficiencies, immunological myelosuppression, impaired erythropoietin production and blood loss from intestinal opportunistic disease.

Management of HIV-associated anemia in highincome countries includes erythropoietin treatment,

\section{Biomed Central}


which has been associated with recovery from anemia and improved survival, but high costs restrict its use in resource-limited settings [13]. Furthermore, studies from Europe and North America have shown that ART itself can be an effective treatment of the anemia of HIV infection [3,14-16]. However, it remains to be seen if the same holds true in rural Africa, where co-morbidities such as micronutrient deficiencies, malaria, TB, parasitic infections and genetic hematological disorders are common. Therefore, we aimed to characterize the anemia and cell indices in a cohort of HIV-infected adults in rural Tanzania, and to study the effect of ART and other factors on the hemoglobin evolution over time.

\section{Methods}

\section{Study setting and participants}

Our study was carried out in Tanzania, a low-income country in East Africa, with an estimated adult HIV prevalence of 5.7\% [17]. Haydom Lutheran Hospital is a 400-bed hospital in Manyara region in northern Tanzania. The hospital is the main health care provider to a rural population of about 260,000 people, in an area where the majority rely on subsistence farming and pastoralism.

The HIV Care and Treatment Centre in Haydom has provided ART free of charge since October 2003. Clinical officers, under supervision of a physician, have been responsible for medical follow-up of patients. Most of the patients who enroll in the HIV program are diagnosed either through voluntary testing and counselling in the villages or testing of hospitalized patients with clinical suspicion of HIV/AIDS. Hence, many patients have advanced immunodeficiency at the time of enrollment.

In the present study we describe the baseline hematological profile in a cohort of treatment-naïve individuals aged 15 years or older who enrolled in HIV care at Haydom Lutheran Hospital between October 2003 and January 2008. In a subset of patients who were anemic at the time they started ART and had a follow-up hemoglobin measurement 12 months later we studied the effect of ART on HIV-associated anemia. Women who were pregnant at baseline or became pregnant during the observation period were excluded from the study, as were women who had given birth within the past 6 weeks, since the physiological hemodilution in pregnancy and subsequent blood loss during delivery would have precluded the results. Ethical approval was obtained from the Medical Research Coordinating Committee of the National Institute for Medical Research in Tanzania and Regional Committee for Medical Research Ethics in Norway. Patients gave written consent to participate in the study.

\section{Treatment, monitoring and laboratory investigations}

ART was initiated in accordance with guidelines from the World Health Organization (WHO) and the National AIDS Control Program [18-21]: WHO stage 4 irrespective of CD4 cell count, WHO stage 3 with CD4 $\leq 350$ cells $/ \mu \mathrm{L}$, or CD $4 \leq 200$ cells $/ \mu \mathrm{L}$ with any WHO stage. However, reliable CD4 cell counts were not available until September 2006, so most patients started ART based on clinical criteria only (WHO stage 3 or 4).

First-line treatment comprised stavudine or zidovudine, combined with lamivudine, and either nevirapine or efavirenz. Regimen choice was subject to availability, with use of a generic fixed-dose combination of stavudine, lamivudine and nevirapine whenever possible. Efavirenz was used in patients with concomitant $T B$ treatment. None of the patients switched to second-line ART during the observation period. Patients with CD4 $\leq 200$ cells $/ \mu \mathrm{L}$ or WHO stage 3 or 4 disease got co-trimoxazole prophylaxis $960 \mathrm{mg}$ thrice weekly or $480 \mathrm{mg}$ daily. Patients were seen by a clinical officer every 3 months, and CD4 cell count and full blood count (including hemoglobin) was scheduled every 3-6 months as part of routine care.

HIV infection was established using two different rapid antibody tests, Determine HIV-1/2 (Abbott laboratories, Abbott Park, IL, USA) and Capillus HIV-1/ 2 (Trinity Biotech, Bray, Co Wicklow, Ireland), in accordance with recommendations from the National AIDS Control Program [21]. Standard hematology was measured using Sysmex KX-21 Hematology Analyzer (Sysmex Corp., Kobe, Japan). Body mass index (BMI, weight in kilograms divided by height in meters squared) was used to assess nutritional status. Body weight was measured at each clinic visit using the same manual scale, and height was measured using a stadiometer mounted on the scale.

Anemia was defined as a hemoglobin level $<12 \mathrm{~g} / \mathrm{dL}$ for women and $<13 \mathrm{~g} / \mathrm{dL}$ for men, in accordance with WHO guidelines [22]. We classified the anemia as mild (10-12 g/dL for women and 10-13 g/dL for men), moderate $(8-10 \mathrm{~g} / \mathrm{dL})$ and severe $(<8 \mathrm{~g} / \mathrm{dL})$. Microcytosis was defined as a mean cell volume $(\mathrm{MCV})<80 \mathrm{fL}$ and hypochromia as a mean corpuscular hemoglobin $(\mathrm{MCH})<26$ pg [23]. In patients who died, anemia was considered a contributing factor if the last hemoglobin before death was $<6.5 \mathrm{~g} / \mathrm{dL}$ [24], or if anemia was recorded as a death cause by the clinician in charge.

\section{Statistical analysis}

In general, we applied the first available laboratory result as the enrollment value. If two values were obtained within a month, the mean was employed. In the study on the effect of ART on HIV-associated anemia, only 
patients who were anemic at the time they started ART and had a follow-up hemoglobin measurement 12 months later were considered. The laboratory result obtained closest to the start of ART was used as baseline, and this value had to be no more than 3 months prior to ART initiation. Laboratory results obtained during the first year on ART were rounded off to the nearest 3 months.

To avoid loss of power we attempted to avoid dichotomization of continuous variables, such as BMI, MCV and $\mathrm{MCH}$ [25]. Instead, BMI was categorized according to recognized cutpoints [26], whereas for MCV and $\mathrm{MCH}$ we used quartiles. Chi-square tests were used to study factors associated with anemia at enrollment. Paired samples T-tests were used to compare hemoglobin levels before and 12 months after ART initiation. Multivariable logistic regression analysis was used to identify predictors of persistent anemia after 12 months of ART. Clinical and laboratory variables were initially examined in bivariable models adjusting for baseline hemoglobin. CD4 cell counts were excluded because of too few observations. All variables with $P<0.2$ in bivariable analyses were then entered in a multivariable model, using the forward stepwise (Wald) method. Multicollinearity was excluded using Spearman's correlation coefficient with a cutoff at 0.7. Data were analysed with SPSS version 16.0 for Windows (SPSS Inc., Chicago, Illinois, USA). All tests were two-sided and level of significance was set at $P<0.05$.

\section{Results}

Patient characteristics at enrollment

A total of $838 \mathrm{HIV}$-infected adults who enrolled in the HIV program between October 3, 2003, and January 31, 2008 , were included in this study (Figure 1). The mean age was 37 years (standard deviation [SD] 10) and 545 patients (65.0\%) were women. Mean BMI was $18.6 \mathrm{~kg} /$ $\mathrm{m}^{2}$ (SD 3.4). At enrollment, 399 patients (47.6\%) had clinical AIDS (WHO stage 4), 245 (29.2\%) had WHO stage 3, 97 (11.6\%) had WHO stage 2, and 97 (11.6\%) had WHO stage 1 disease. Ninety-eight patients $(11.7 \%)$ were on TB treatment when they enrolled in care.

The mean hemoglobin at enrollment was $10.3 \mathrm{~g} / \mathrm{dL}$ (SD 2.4), the mean MCV was $82.5 \mathrm{fL}$ (SD 7.8), and the mean $\mathrm{MCH}$ was $26.6 \mathrm{pg}$ (SD 3.2). Overall, 649 of 838 patients $(77.4 \%)$ met the definition of anemia: 269 patients (32.1\%) had mild anemia, 238 (28.4\%) had moderate anemia, and 142 (16.9\%) had severe anemia. Out of 649 anemic patients, 254 (39.1\%) had microcytosis and hypochromia, suggestive of iron deficiency, whereas $52(8.0 \%)$ had hypochromia with normocytosis, and 18 (2.8\%) had microcytosis with normochromia.

Table 1 gives an overview of patient characteristics at enrollment and associations with anemia. Female

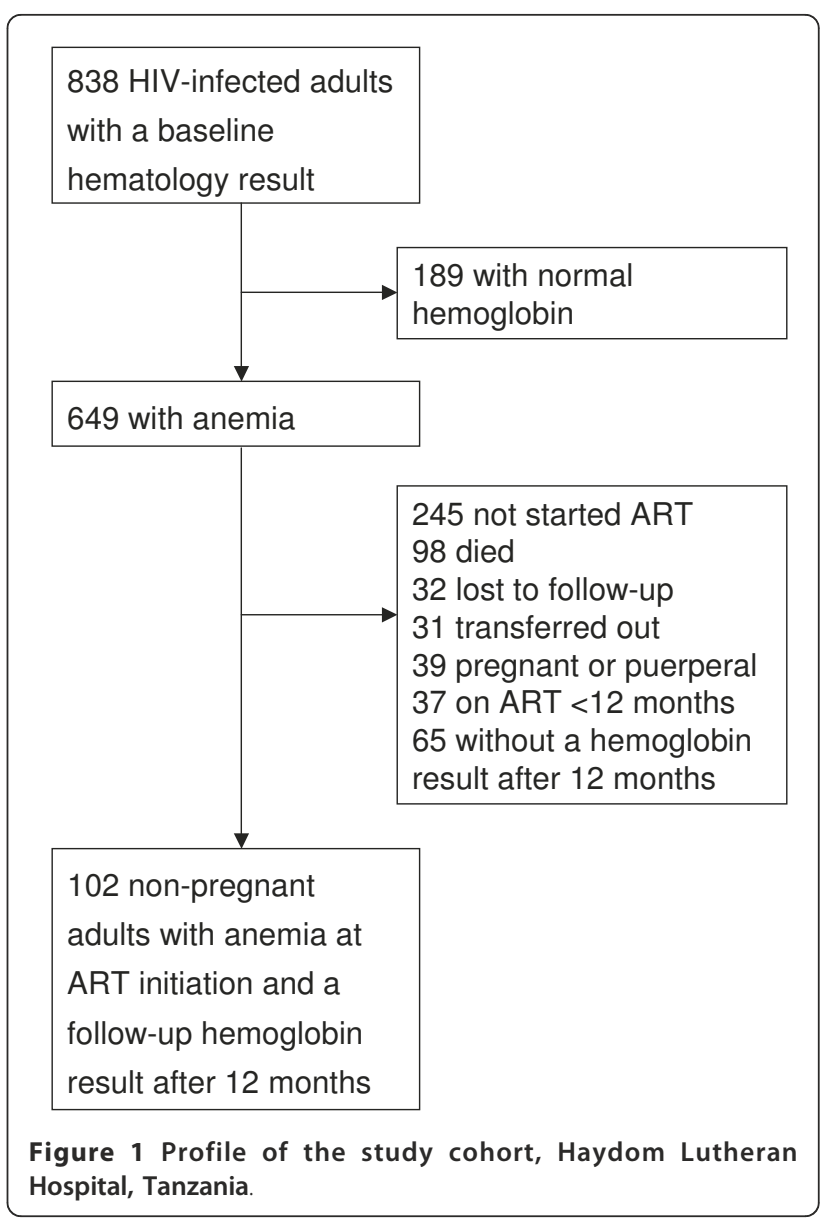

gender, clinical AIDS, TB, low BMI, microcytosis and hypochromia were all significantly associated with anemia at enrollment.

\section{Hemoglobin evolution during antiretroviral treatment}

Out of 838 adults included in the study, 102 patients who were anemic at ART initiation and had a follow-up hemoglobin measurement 12 months later were selected for the sub-study on ART and anemia. Reasons for not being included in this sub-study are given in figure 1 .

Among 102 patients in this sub-study, the mean age was 36 years (SD 10) and 75 patients (73.5\%) were women. Mean BMI was $18.2 \mathrm{~kg} / \mathrm{m}^{2}$ (SD 3.3). Sixty-one patients $(59.8 \%)$ had clinical AIDS at ART initiation. Fourteen patients $(13.7 \%)$ were on TB treatment when they initiated ART and 8 more started TB treatment during the observation period of 12 months. Initial ART regimen was stavudine/lamivudine/nevirapine in 62 patients $(60.8 \%)$, stavudine/lamivudine/efavirenz in 17 (16.7\%), zidovudine/lamivudine/nevirapine in 16 (15.7\%), and zidovudine/lamivudine/efavirenz in 7 (6.9\%). Only 17 patients had a baseline CD4 measurement; the mean CD4 cell count was 140 cells/ $\mu \mathrm{L}$ (SD 149). 
Table 1 Patient characteristics and degree of anemia at enrollment

\begin{tabular}{|c|c|c|c|c|c|}
\hline Variables & $\begin{array}{c}\text { Normal } \\
\text { n (\%) }\end{array}$ & $\begin{array}{c}\text { Mild anemia }^{a} \\
\text { n (\%) }\end{array}$ & $\begin{array}{c}\text { Moderate anemiab } \\
\text { n (\%) }\end{array}$ & $\begin{array}{l}\text { Severe anemia }{ }^{c} \\
n(\%)\end{array}$ & $P$ \\
\hline All $(n=838)$ & 189 (22.6) & $269(32.1)$ & $238(28.4)$ & $142(16.9)$ & \\
\hline Gender & & & & & 0.046 \\
\hline Female & $115(21.1)$ & $165(30.3)$ & $171(31.4)$ & $94(17.2)$ & \\
\hline Male & $74(25.2)$ & $104(35.5)$ & $67(22.9)$ & $48(16.4)$ & \\
\hline Age (years) & & & & & 0.726 \\
\hline$<30$ & $40(20.1)$ & $61(30.7)$ & $61(30.7)$ & 37 (18.6) & \\
\hline $30-39$ & $75(22.1)$ & $106(31.3)$ & $98(28.9)$ & $60(17.7)$ & \\
\hline$\geq 40$ & $74(24.7)$ & $102(34.0)$ & $79(26.3)$ & $45(15.0)$ & \\
\hline AIDS $^{d}$ & & & & & $<0.001$ \\
\hline Yes & $48(12.0)$ & $109(27.3)$ & $146(36.6)$ & $96(24.1)$ & \\
\hline No & $141(32.1)$ & $160(36.4)$ & $92(21.0)$ & $46(10.5)$ & \\
\hline Tuberculosis $^{\mathrm{e}}$ & & & & & 0.001 \\
\hline Yes & $9(9.2)$ & $34(34.7)$ & 28 (28.6) & $27(27.5)$ & \\
\hline No & $180(24.3)$ & 235 (31.8) & $210(28.4)$ & $115(15.5)$ & \\
\hline BMI $(\mathrm{kg} / \mathrm{m} 2)^{\mathrm{f}}$ & & & & & $<0.001$ \\
\hline$<16$ & $17(8.8)$ & $49(25.4)$ & $67(34.7)$ & $60(31.1)$ & \\
\hline $16-18.4$ & 46 (19.7) & 74 (31.8) & 76 (32.6) & $37(15.9)$ & \\
\hline$\geq 18.5$ & 118 (33.5) & $134(38.1)$ & 76 (21.6) & $24(6.8)$ & \\
\hline MCV (fL) & & & & & $<0.001$ \\
\hline$<80$ & $36(11.7)$ & $90(29.2)$ & $116(37.7)$ & $66(21.4)$ & \\
\hline$\geq 80$ & $153(28.9)$ & 179 (33.8) & $122(23.0)$ & $76(14.3)$ & \\
\hline $\mathrm{MCH}(\mathrm{pg})$ & & & & & $<0.001$ \\
\hline$<26$ & $35(10.3)$ & 95 (27.9) & $130(38.1)$ & $81(23.7)$ & \\
\hline$\geq 26$ & $154(31.0)$ & $174(35.0)$ & $108(21.7)$ & $61(12.3)$ & \\
\hline
\end{tabular}

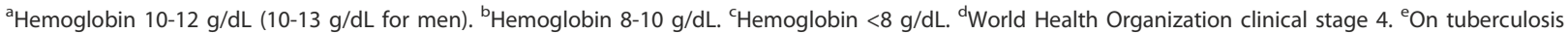
treatment at enrollment. ${ }^{\mathrm{f}} 60$ values missing $(n=778)$.

$\mathrm{BMI}$, body mass index; MCV, mean cell volume; $\mathrm{MCH}$, mean corpuscular hemoglobin.

At the time of ART initiation the mean hemoglobin was $9.9 \mathrm{~g} / \mathrm{dL}$ (SD 1.5). Eleven patients (10.8\%) had severe anemia, 37 (36.3\%) had moderate anemia and 54 (52.9\%) had mild anemia. Patients with severe anemia were less likely to start a zidovudine-containing initial regimen $(1$ of $11 ; 9.1 \%)$ than patients with moderate $(8$ of $37 ; 21.6 \%$ ) or mild anemia (14 of $54 ; 25.9 \%)$, but the difference was not statistically significant $(P=0.470)$. After receiving ART for 12 months the mean hemoglobin increased to $12.4 \mathrm{~g} / \mathrm{dL}$ (SD 1.9) $(P<0.001)$ (Figure $2)$; however, 39 patients (38.2\%) were still anemic, of whom 2 (2.0\%) had severe anemia, 7 (6.9\%) had moderate anemia and $30(29.4 \%)$ had mild anemia. The two patients with severe anemia at 12 months both had a falling hemoglobin level during ART. The greatest hemoglobin change $(+4.6 \mathrm{~g} / \mathrm{dL})$ was seen in patients with severe anemia at the time of ART initiation, compared to $+3.0 \mathrm{~g} / \mathrm{dL}$ in patients with moderate anemia and $+1.8 \mathrm{~g} / \mathrm{dL}$ in patients with mild anemia.

To assess whether the hemoglobin increase could be a result of other factors associated with enrollment in HIV care rather than ART itself, we studied the hemoglobin evolution in 18 non-pregnant adults who were anemic at enrollment and had a follow-up hemoglobin measurement 12 months later, but did not start ART. In this group there was no statistically significant hemoglobin increase: the mean hemoglobin was $10.1 \mathrm{~g} / \mathrm{dL}$ (SD 1.5) at enrollment and $10.9 \mathrm{~g} / \mathrm{dL}$ (SD 2.1) after 12

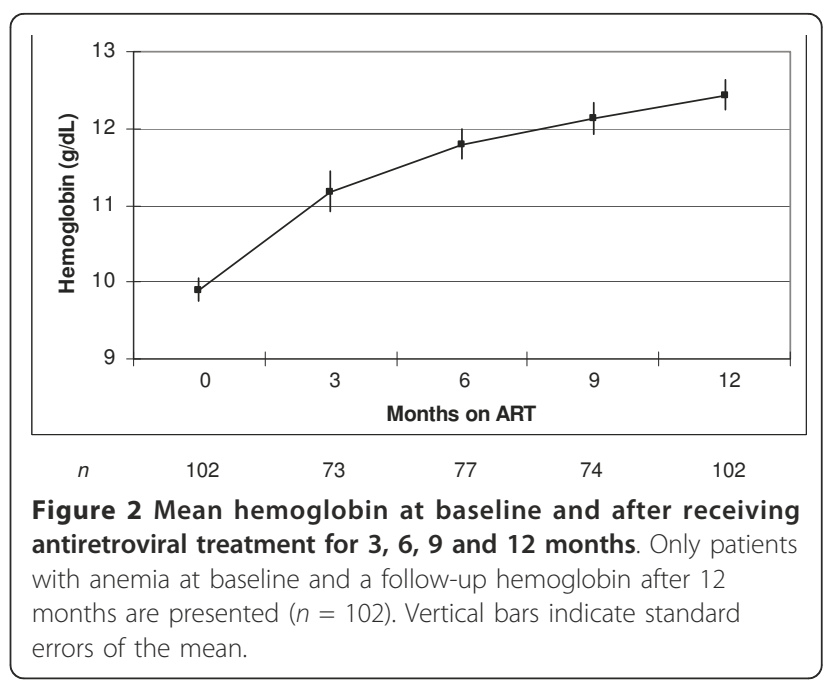


months $(P=0.191)$. Adjusted for baseline hemoglobin, patients who did not start ART had a 6-fold increased risk of persistent anemia after 12 months compared to those who started ART (Odds Ratio [OR] 5.99; 95\% confidence interval $[\mathrm{CI}] 1.82-19.8 ; P=0.003)$.

Sixty-five patients who were alive and in care 12 months after ART initiation, but who did not have a follow-up hemoglobin measurement, were excluded from our analysis. These patients had a similar age (mean 38 years) and sex (67.7\% female) distribution as in the main analysis. Forty-one of these patients had a hemoglobin measurement at 9 months, and they showed a similar improvement as patients in the main analysis, from a mean hemoglobin of $9.6 \mathrm{~g} / \mathrm{dL}(\mathrm{SD} 1.8)$ at baseline to $12.3 \mathrm{~g} / \mathrm{dL}$ (SD 1.6) at 9 months $(P<0.001)$.

Ninety-eight patients who died during the first year on ART were also excluded from our analysis, 68 of whom died within the first three months. At the time of ART initiation the mean hemoglobin among patients who died was $8.8 \mathrm{~g} / \mathrm{dL}$ (SD 1.7), significantly lower than among patients in the main analysis $(P<0.001)$. We reviewed the records of these patients and found that anemia contributed to the death in 15 of 98 patients. Thirteen of 15 anemia-related deaths occurred in patients who received a stavudine-containing regimen, of whom 8 had severe anemia already at the time of ART initiation. Two patients died of presumed hematotoxic effects of zidovudine, 58 and 94 days after ART initiation, respectively.

\section{Predictors of persistent anemia}

Among patients who were anemic at ART initiation, only MCV in the lower quartile ( $<76.0 \mathrm{fL}$ ) significantly predicted persistent anemia 12 months later in bivariable logistic regression analysis adjusted for baseline hemoglobin, whereas $\mathrm{MCH}$ in the lower quartile $(<23.8$ pg) and a zidovudine-containing initial regimen were borderline significant (Table 2). MCV and $\mathrm{MCH}$ were collinear (Spearman's correlation coefficient 0.86); hence, only MCV was included in the multivariable model. In the final multivariable analysis, $\mathrm{MCV}$ in the lower quartile (OR 4.34; 95\% CI 1.22-15.5; $P=0.023$ ) and a zidovudine-containing initial regimen (OR 2.91; 95\% CI 1.03-8.19; $P=0.043$ ) were significantly associated with persistent anemia.

During the first year on ART, 3 patients switched from stavudine to zidovudine and 4 from zidovudine to stavudine, 2 of whom switched because of severe anemia. To assess whether drug substitutions might have confounded our results, we conducted a sensitivity analysis where these patients were excluded. In the resulting multivariable model, both $\mathrm{MCV}$ in the lower quartile (OR 4.30; 95\% CI 1.16-15.9; $P=0.029)$ and a zidovudine-containing initial regimen (OR 3.32; 95\% CI
1.10-10.0; $P=0.034)$ remained strong and significant predictors of persistent anemia.

\section{Discussion}

In this study $77.4 \%$ of HIV-infected adults had anemia at the time they enrolled in HIV care. Women were more likely than men to be anemic, reflecting the overall higher prevalence of anemia in women due to menstrual blood loss and multiple deliveries. Furthermore, anemia at enrollment was associated with advanced immunodeficiency (WHO stage 4 and low BMI) and TB, in line with previous studies $[9-11,27,28]$. The overall prevalence of anemia was much higher in our study than in studies from high-income countries, but comparable to results from certain other African countries such as Nigeria, Côte d'Ivoire, Malawi and South Africa $[2,29,30]$, probably because of more advanced immunodeficiency at enrollment as well as higher prevalence of anemia in the general population in sub-Saharan Africa [22]. Interestingly, in a recent study from our study site the mean hemoglobin among HIV-negative healthy adults (58.8\% females, mean age 32.6 years) was $13.2 \mathrm{~g} /$ $\mathrm{dL}$, compared to $10.3 \mathrm{~g} / \mathrm{dL}$ among HIV-positive adults in our study [31]. In other words, anemia is far more frequent in HIV-infected adults in this region than in their HIV-negative counterparts.

The hemoglobin level increased significantly in patients who received ART; on average the hemoglobin increased $2.5 \mathrm{~g} / \mathrm{dL}$ over the first 12 months among patients who were anemic at ART initiation. Previous studies have reported that ART is associated with resolution of HIV-associated anemia in Europe and North America $[3,14,15]$. More recently, similar findings have been reported from sub-Saharan Africa. In a study from Abidjan, Côte d'Ivoire, the prevalence of anemia (hemoglobin $<10.5 \mathrm{~g} / \mathrm{dL}$ ) decreased from $31 \%$ at baseline to $17 \%$ after 6 months on a zidovudine-containing ART regimen [32]. A study from rural Uganda found that the mean hemoglobin increased from $11.3 \mathrm{~g} / \mathrm{dL}$ at baseline to $12.8 \mathrm{~g} / \mathrm{dL}$ after 12 months on ART [33]. Finally, a recent study from Kampala, Uganda, reported that the median hemoglobin increased by $2.9 \mathrm{~g} / \mathrm{dL}$ during the first 6 months of ART among patients who were anemic (hemoglobin $<9.5 \mathrm{~g} / \mathrm{dL}$ ) at ART initiation [34]. Although the magnitude of the hemoglobin increase might vary depending on the baseline hemoglobin level and degree of immunodeficiency, our study confirms that HIV-associated anemia in rural Tanzania, as in industrialized countries, can be reversed by ART in the majority of subjects. This suggests that HIV-associated anemia in this setting is caused mainly by factors related to the HIV infection itself, such as chronic inflammation and opportunistic infections, rather than tropical diseases or specific environmental factors. 
Table 2 Predictors of persistent anemia after 12 months of ART among 102 HIV-infected adults who were anemic at ART initiation

\begin{tabular}{|c|c|c|c|c|c|c|}
\hline \multirow[b]{2}{*}{ Variables } & \multirow[b]{2}{*}{ Total } & \multirow[b]{2}{*}{ Anemic after 12 months (\%) } & \multicolumn{2}{|c|}{ Crude $^{a}$} & \multicolumn{2}{|c|}{ Adjusted $^{\mathbf{b}}$} \\
\hline & & & OR $(95 \% \mathrm{Cl})$ & $P$ & OR $(95 \% \mathrm{Cl})$ & $P$ \\
\hline \multicolumn{7}{|l|}{ Gender } \\
\hline Female & 75 & $30(40.0)$ & 1 & & & \\
\hline Male & 27 & $9(33.3)$ & $0.85(0.33-2.20)$ & 0.744 & & \\
\hline \multicolumn{7}{|l|}{ Age (years) } \\
\hline$<30$ & 26 & $10(38.5)$ & 1 & & & \\
\hline $30-39$ & 42 & $19(45.2)$ & $1.45(0.52-4.01)$ & 0.476 & & \\
\hline$\geq 40$ & 34 & $10(29.4)$ & $0.77(0.25-2.33)$ & 0.641 & & \\
\hline \multicolumn{7}{|l|}{$\operatorname{AIDS}^{\mathrm{C}}$} \\
\hline No & 41 & $16(39.0)$ & 1 & & & \\
\hline Yes & 61 & $23(37.7)$ & $0.93(0.41-2.13)$ & 0.862 & & \\
\hline \multicolumn{7}{|l|}{ Tuberculosis $^{d}$} \\
\hline No & 80 & $31(38.8)$ & 1 & & & \\
\hline Yes & 22 & $8(36.4)$ & $0.69(0.24-1.94)$ & 0.477 & & \\
\hline \multicolumn{7}{|l|}{$\mathrm{BMI}\left(\mathrm{kg} / \mathrm{m}^{2}\right)$} \\
\hline$<16$ & 26 & $9(34.6)$ & 1 & & & \\
\hline $16-18.4$ & 35 & $15(42.9)$ & $1.62(0.55-4.78)$ & 0.382 & & \\
\hline$\geq 18.5$ & 40 & $14(35.0)$ & $1.24(0.42-3.64)$ & 0.702 & & \\
\hline \multicolumn{7}{|l|}{$M C V(f L)$} \\
\hline$\geq 87.5$ & 25 & $6(24.0)$ & 1 & & 1 & \\
\hline $82.1-87.4$ & 27 & $9(33.3)$ & $1.47(0.43-5.06)$ & 0.538 & $1.35(0.38-4.72)$ & 0.644 \\
\hline $76.0-82.0$ & 25 & $9(36.0)$ & $1.75(0.51-6.00)$ & 0.377 & $1.42(0.39-5.13)$ & 0.595 \\
\hline$<76.0$ & 25 & $15(60.0)$ & $4.05(1.17-14.1)$ & 0.028 & $4.34(1.22-15.5)$ & 0.023 \\
\hline \multicolumn{7}{|l|}{$\mathrm{MCH}(\mathrm{pg})$} \\
\hline$\geq 28.1$ & 26 & $7(26.9)$ & 1 & & & \\
\hline $26.6-28.0$ & 24 & $7(29.2)$ & $1.14(0.33-3.95)$ & 0.841 & & \\
\hline $23.8-26.5$ & 26 & $10(38.5)$ & $1.70(0.52-5.52)$ & 0.380 & & \\
\hline$<23.8$ & 26 & $15(57.7)$ & $3.20(0.97-10.5)$ & 0.056 & & \\
\hline \multicolumn{7}{|l|}{ Initial regimen } \\
\hline Stavudine & 79 & $27(34.2)$ & 1 & & 1 & \\
\hline Zidovudine & 23 & $12(52.2)$ & $2.46(0.93-6.54)$ & 0.071 & $2.91(1.03-8.19)$ & 0.043 \\
\hline
\end{tabular}

${ }^{a}$ Adjusted for baseline hemoglobin. ${ }^{b}$ Adjusted for baseline hemoglobin and the other variables listed in the final model. MCH was excluded because of collinearity with MCV. ${ }^{c}$ World Health Organization clinical stage $4 .{ }^{d}$ On tuberculosis treatment at ART initiation or started within the observation period of 12 months.

$\mathrm{OR}$, odds ratio; $\mathrm{Cl}$, confidence interval; $\mathrm{BMI}$, body mass index; $\mathrm{MCV}$, mean cell volume; $\mathrm{MCH}$, mean corpuscular hemoglobin.

However, not all patients on ART achieved a normal hemoglobin level. A low MCV was a strong and independent predictor of persistent anemia in our study. Microcytosis was also associated with persistent anemia in the Women's Interagency HIV Study in USA [15], and with an increased risk of developing severe anemia in a recent study from Uganda [34]. Classically, the most common cause of microcytosis is iron deficiency [35], which would explain why these patients were less likely to recover from anemia. On the other hand, iron supplementation in HIV is controversial, as there is evidence of iron accumulation and enhanced oxidative stress with progression of HIV infection [36]. Interestingly, in a study from Malawi only $16 \%$ of patients with severe HIV-associated anemia (hemoglobin $<7 \mathrm{~g} / \mathrm{dL}$ ) had iron deficiency, whereas $19 \%$ had iron excess, assessed by bone marrow examination [37]. Moreover, a large study from Gambia found that elevated iron status strongly predicted mortality in HIV-infected adults [38]. In sub-Saharan Africa iron supplementation is commonly prescribed or self-supplemented; hence, there is a need for further studies to clarify its role in patients with HIV-associated anemia.

An initial zidovudine-containing ART regimen was also associated with persistent anemia in our study, increasing the risk by nearly 3 times compared to regimens containing stavudine. The potential myelosuppressive effect of zidovudine has been known for more than two decades [39], but its significance in clinical practice is still debated. For instance, a recent study from 
Uganda did not find an increased risk of early severe anemia (hemoglobin $\leq 8 \mathrm{~g} / \mathrm{dL}$ within 6 months of ART initiation) in patients on zidovudine, and concluded that zidovudine - in the absence of better alternatives should not be withheld even in patient with a hemoglobin below $8 \mathrm{~g} / \mathrm{dL}$ at the time of ART initiation. However, the same study reported that anemic patients (hemoglobin $\leq 9.5 \mathrm{~g} / \mathrm{dL}$ ) who started a stavudine-containing regimen had a significantly larger hemoglobin increase than those who started zidovudine $(3.1 \mathrm{~g} / \mathrm{dL}$ vs. $2.5 \mathrm{~g} / \mathrm{dL}$ ) [34]. This is in line with a meta-analysis of 6 randomized trials, in which the mean hemoglobin level was $0.8 \mathrm{~g} / \mathrm{dL}$ lower in patients who received zidovudine than those who received stavudine after 48 weeks on ART [40]. These differences are small, but the EuroSIDA study indicated that even subtle differences in hemoglobin level might be of clinical significance; indeed, a $1 \mathrm{~g} / \mathrm{dL}$ decrease in the latest hemoglobin level increased the hazard of death by $57 \%$, after adjusting for demographic factors, ART regimen, AIDS status, CD4 cell count and viral load [3]. The 2010 revision of the WHO guidelines for resource-limited settings recommend to start ART with a regimen consisting of zidovudine or tenofovir in combination with lamivudine and a non-nucleoside reverse transcriptase inhibitor, in order to avoid the long-term toxicities of stavudine [24]. Our study underscores the possible caveats of zidovudine, and suggests that other drugs might be preferable in anemic patients, especially in countries where anemia is endemic.

Before the HIV era, recommendations for management of anemia in classical tropical medicine included screening for malaria, treatment for helminthic infections and iron/folic acid supplementation [41]. In the setting of a generalized HIV epidemic, which is the case in most of sub-Saharan Africa, however, these guidelines are overdue for revision, since HIV-associated anemia requires a different approach. Indeed, in a study of patients admitted at a large urban hospital in Malawi with severe anemia (hemoglobin $<7 \mathrm{~g} / \mathrm{dL}$ ), $79 \%$ had HIV and $37 \%$ had TB, and relatively few had classical causes of anemia such as heavy hookworm infections (9\%), malaria (14\%) or iron deficiency (25\%) [37]. Management of anemia in settings with a high prevalence of HIV should always include an HIV test, and ART should be initiated if no other explanation of the anemia can be identified. Our study suggests that this would be sufficient to correct the anemia in the majority of subjects, and that MCV can be a useful additional test to identify patients in whom additional treatment (such as iron supplementation) might be required.

There were some limitations of our study. Most importantly there may have been a selection bias towards patients with a more favorable prognosis in the sub-study on the effect of ART on anemia, since we only included patients with a follow-up hemoglobin measurement after 12 months. Patients who died during the first year on ART might have had a different hemoglobin evolution, but since the majority of deaths occurred within the first 3 months, few of these had a second laboratory measurement. We also excluded patients who were still receiving ART, but did not have a hemoglobin measurement after 12 months. If these patients were less likely to be anemic than the others, our results could be biased (selection by indication); however, patients who were excluded had a similar hemoglobin increase at 9 months as the patients in our main analysis. Furthermore, our study was limited by lack of adherence data, and it is possible that poor adherence contributed to persistent anemia in some patients. On the other hand, in a previous study from the same cohort, we found that $94.8 \%$ of patients had suppressed viraemia after 1 year of ART, indicating good adherence in the majority of subjects [42]. Finally, given the observational nature of the study, the lack of randomization made comparison between different ART regimens susceptible to bias. For instance, patients with severe anemia at baseline were less likely to receive a zidovudine-containing regimen; however, we adjusted for baseline hemoglobin in the logistic regression models. Nevertheless, our results may have been influenced by other confounding factors and bias not accounted for in the analysis.

\section{Conclusions}

In conclusion, we found that the majority of patients who enrolled in HIV care at a rural hospital in Tanzania were anemic, and that nearly $40 \%$ of the anemic patients had microcytosis and hypochromia suggestive of iron deficiency. Patients who were anemic at the time of ART initiation had a strong and significant hemoglobin increase over the initial 12 months of ART. However, more than one third of patients did not reach normal hemoglobin levels while on ART, and a low MCV and a zidovudine-containing initial regimen were independent predictors of persistent anemia. Our study indicate that although ART effectively reverses HIV-associated anemia in the majority of individuals, additional interventions might be warranted in a subset of patients.

\section{Acknowledgements}

We are indebted to the patients who participated in the study. We acknowledge the staff at Haydom HIV Care and Treatment Centre, the hospital management, the Ministry of Health, and the National AIDS Control Program for collaboration and support. The study was supported by grants from the Scientific Council at Oslo University Hospital (Vitenskapsradet Ulleval), and South-Eastern Norway Regional Health Authority (Helse Sor-Ost RHF). 


\section{Author details}

'Department of Infectious Diseases, Oslo University Hospital, Ulleval, Oslo, Norway. ${ }^{2}$ HIV Care and Treatment Centre, Haydom Lutheran Hospital, Mbulu, Tanzania. ${ }^{3}$ Research Unit, Sorlandet Hospital, Kristiansand, Norway. ${ }^{4}$ Centre for Development Studies, University of Agder, Kristiansand, Norway. ${ }^{5}$ Institute of Clinical Medicine, University of Tromso, Tromso, Norway. ${ }^{6}$ Medical Department, University Hospital of North Norway, Tromso, Norway.

\section{Authors' contributions}

AJ analyzed the data and drafted the manuscript. EN collected the data. SGG and JNB conceived the study and participated in its design and coordination. All authors critically revised the manuscript and approved the final version.

\section{Competing interests}

The authors declare that they have no competing interests.

Received: 9 January 2011 Accepted: 11 July 2011

Published: 11 July 2011

\section{References}

1. Harris RJ, Sterne JA, Abgrall S, Dabis F, Reiss P, Saag M, Phillips AN, Chene G, Gill JM, Justice AC, et al: Prognostic importance of anaemia in HIV type-1-infected patients starting antiretroviral therapy: collaborative analysis of prospective cohort studies. Antivir Ther 2008, 13:959-967.

2. May M, Boulle A, Phiri S, Messou E, Myer L, Wood R, Keiser O, Sterne JA, Dabis F, Egger M: Prognosis of patients with HIV-1 infection starting antiretroviral therapy in sub-Saharan Africa: a collaborative analysis of scale-up programmes. Lancet 2010, 376:449-457.

3. Mocroft A, Kirk O, Barton SE, Dietrich M, Proenca R, Colebunders R, Pradier C, dArminio MA, Ledergerber B, Lundgren JD: Anaemia is an independent predictive marker for clinical prognosis in HIV-infected patients from across Europe. EuroSIDA study group. AIDS 1999, 13:943-950.

4. Stringer JS, Zulu I, Levy J, Stringer EM, Mwango A, Chi BH, Mtonga V, Reid S, Cantrell RA, Bulterys M, et al: Rapid scale-up of antiretroviral therapy at primary care sites in Zambia: feasibility and early outcomes. JAMA 2006, 296:782-793.

5. Etard JF, Ndiaye I, Thierry-Mieg M, Gueye NF, Gueye PM, Laniece I, Dieng AB, Diouf A, Laurent C, Mboup S, et al: Mortality and causes of death in adults receiving highly active antiretroviral therapy in Senegal: a 7-year cohort study. AIDS 2006, 20:1181-1189.

6. Johannessen A, Naman E, Ngowi BJ, Sandvik L, Matee MI, Aglen HE, Gundersen SG, Bruun JN: Predictors of mortality in HIV-infected patients starting antiretroviral therapy in a rural hospital in Tanzania. BMC Infect Dis 2008, 8:52.

7. Moore RD, Keruly JC, Chaisson RE: Anemia and survival in HIV infection. J Acquir Immune Defic Syndr Hum Retrovirol 1998, 19:29-33.

8. Russell EC, Charalambous S, Pemba L, Churchyard GJ, Grant AD, Fielding K: Low haemoglobin predicts early mortality among adults starting antiretroviral therapy in an HIV care programme in South Africa: a cohort study. BMC Public Health 2010, 10:433.

9. Sullivan PS, Hanson DL, Chu SY, Jones JL, Ward JW: Epidemiology of anemia in human immunodeficiency virus (HIV)-infected persons: results from the multistate adult and adolescent spectrum of HIV disease surveillance project. Blood 1998, 91:301-308.

10. Mugisha JO, Shafer LA, Van der Paal L, Mayanja BN, Eotu H, Hughes P, Whitworth JA, Grosskurth H: Anaemia in a rural Ugandan HIV cohort: prevalence at enrolment, incidence, diagnosis and associated factors. Trop Med Int Health 2008, 13:788-794.

11. Obirikorang C, Yeboah FA: Blood haemoglobin measurement as a predictive indicator for the progression of HIV/AIDS in resource-limited setting. J Biomed Sci 2009, 16:102.

12. Semba RD, Gray GE: Pathogenesis of anemia during human immunodeficiency virus infection. J Investig Med 2001, 49:225-239.

13. Volberding PA, Levine AM, Dieterich D, Mildvan D, Mitsuyasu R, Saag M: Anemia in HIV infection: clinical impact and evidence-based management strategies. Clin Infect Dis 2004, 38:1454-1463.

14. Moore RD, Forney D: Anemia in HIV-infected patients receiving highly active antiretroviral therapy. J Acquir Immune Defic Syndr 2002, 29:54-57.
15. Berhane K, Karim R, Cohen MH, Masri-Lavine L, Young M, Anastos K, Augenbraun M, Watts DH, Levine AM: Impact of highly active antiretroviral therapy on anemia and relationship between anemia and survival in a large cohort of HIV-infected women: Women's Interagency HIV Study. J Acquir Immune Defic Syndr 2004, 37:1245-1252.

16. Semba RD, Shah N, Klein RS, Mayer KH, Schuman P, Gardner LI, Vlahov D: Highly active antiretroviral therapy associated with improved anemia among HIV-infected women. AIDS Patient Care STDS 2001, 15:473-480.

17. Joint United Nations Programme on HIV/AIDS, World Health Organization: AIDS Epidemic Update: December 2009 Geneva: UNAIDS; 2009.

18. World Health Organization: Scaling up antiretroviral therapy in resourcelimited settings. Guidelines for a public health approach Geneva: WHO; 2002.

19. World Health Organization: Scaling up antiretroviral therapy in resourcelimited settings: Treatment guidelines for a public health approach. 2003 revision Geneva: WHO; 2004.

20. World Health Organization: Antiretroviral therapy for HIV infection in adults and adolescents: Recommendations for a public health approach. 2006 revision Geneva: WHO; 2006.

21. National AIDS Control Program: Guidelines for health workers in the management of HIV/AIDS in Tanzania Dar es Salaam: Ministry of Health; 2004.

22. World Health Organization: Worldwide prevalence of anaemia 1993-2005. WHO Global Database on Anaemia Geneva: WHO; 2008.

23. McKenzie SB: Clinical Laboratory Hematology New Jersey: Prentice Hall; 2004.

24. World Health Organization: Antiretroviral therapy for HIV infection in adults and adolescents. Recommendations for a public health approach. 2010 revision Geneva: WHO; 2010.

25. Royston P, Altman DG, Sauerbrei W: Dichotomizing continuous predictors in multiple regression: a bad idea. Stat Med 2006, 25:127-141.

26. Ferro-Luzzi A, Sette S, Franklin M, James WP: A simplified approach of assessing adult chronic energy deficiency. Eur J Clin Nutr 1992, 46:173-186.

27. Firnhaber C, Smeaton L, Saukila N, Flanigan T, Gangakhedkar R, Kumwenda J, La Rosa A, Kumarasamy N, De Gruttola V, Hakim JG, et al: Comparisons of anemia, thrombocytopenia, and neutropenia at initiation of HIV antiretroviral therapy in Africa, Asia, and the Americas. Int J Infect Dis 2010, 14:e1088-1092.

28. Subbaraman R, Devaleenal B, Selvamuthu P, Yepthomi T, Solomon SS, Mayer $\mathrm{KH}$, Kumarasamy N: Factors associated with anaemia in HIVinfected individuals in southern India. Int J STD AIDS 2009, 20:489-492.

29. Erhabor O, Ejele OA, Nwauche CA, Buseri Fl: Some haematological parameters in human immunodeficiency virus (HIV) infected Africans: the Nigerian perspective. Niger J Med 2005, 14:33-38.

30. Omoregie R, Omokaro EU, Palmer O, Ogefere HO, Egbeobauwaye A, Adeghe JE, Osakue SI, Ihemeje V: Prevalence of anaemia among HIVinfected patients in Benin City, Nigeria. Tanzan J Health Res 2009, 11:1-4.

31. Ngowi BJ, Mfinanga SG, Bruun JN, Morkve O: Immunohaematological reference values in human immunodeficiency virus-negative adolescent and adults in rural northern Tanzania. BMC Infect Dis 2009, 9:1.

32. Moh R, Danel C, Sorho S, Sauvageot D, Anzian A, Minga A, Gomis OB, Konga C, Inwoley A, Gabillard D, et al: Haematological changes in adults receiving a zidovudine-containing HAART regimen in combination with cotrimoxazole in Cote d'Ivoire. Antivir Ther 2005, 10:615-624.

33. Forna F, Moore D, Mermin J, Brooks JT, Were W, Buchacz K, Campbell JD, Downing R, Borkowf CB, Weidle PJ: Hematologic changes associated with Zidovudine following single-drug substitution from stavudine in a home-based AIDS care program in rural Uganda. J Int Assoc Physicians AIDS Care (Chic III) 2009, 8:128-138.

34. Kiragga AN, Castelnuovo B, Nakanjako D, Manabe YC: Baseline severe anaemia should not preclude use of zidovudine in antiretroviral-eligible patients in resource-limited settings. J Int AIDS Soc 2010, 13:42.

35. Wallerstein RO Jr: Laboratory evaluation of anemia. West J Med 1987, 146:443-451.

36. Boelaert JR, Weinberg GA, Weinberg ED: Altered iron metabolism in HIV infection: mechanisms, possible consequences, and proposals for management. Infect Agents Dis 1996, 5:36-46.

37. Lewis DK, Whitty CJ, Walsh AL, Epino H, Broek NR, Letsky EA, Munthali C, Mukiibi JM, Boeree MJ: Treatable factors associated with severe anaemia in adults admitted to medical wards in Blantyre, Malawi, an area of high HIV seroprevalence. Trans R Soc Trop Med Hyg 2005, 99:561-567. 
38. McDermid JM, Jaye A, Schim van der Loeff MF, Todd J, Bates C, Austin S, Jeffries D, Awasana AA, Whittlex AA, Prentice A: Elevated iron status strongly predicts mortality in West African adults with HIV infection. $J$ Acquir Immune Defic Syndr 2007, 46:498-507.

39. Gelmon K, Montaner JS, Fanning M, Smith JR, Falutz J, Tsoukas C, Gill J, Wells $G$, O'Shaughnessy M, Wainberg $M$, et al: Nature, time course and dose dependence of zidovudine-related side effects: results from the Multicenter Canadian Azidothymidine Trial. AIDS 1989, 3:555-561.

40. Moyle G, Sawyer W, Law M, Amin J, Hill A: Changes in hematologic parameters and efficacy of thymidine analogue-based, highly active antiretroviral therapy: a meta-analysis of six prospective, randomized, comparative studies. Clin Ther 2004, 26:92-97.

41. Watson-Williams EJ: Anaemia in the tropics. Br Med J 1968, 4:34-38,

42. Johannessen A, Naman E, Kivuyo SL, Kasubi MJ, Holberg-Petersen M, Matee MI, Gundersen SG, Bruun JN: Virological efficacy and emergence of drug resistance in adults on antiretroviral treatment in rural Tanzania. BMC Infect Dis 2009, 9:108.

Pre-publication history

The pre-publication history for this paper can be accessed here: http://www.biomedcentral.com/1471-2334/11/190/prepub

doi:10.1186/1471-2334-11-190

Cite this article as: Johannessen et al:: Antiretroviral treatment reverses HIV-associated anemia in rural Tanzania. BMC Infectious Diseases 2011 $11: 190$

\section{Submit your next manuscript to BioMed Central} and take full advantage of:

- Convenient online submission

- Thorough peer review

- No space constraints or color figure charges

- Immediate publication on acceptance

- Inclusion in PubMed, CAS, Scopus and Google Scholar

- Research which is freely available for redistribution

Submit your manuscript at www.biomedcentral.com/submit 